\title{
IMPACT OF FUNGICIDE TREATMENTS APPLIED TO WHEAT CROP (Triticum aestivum L.) ON SEED PATHOGENS
}

\author{
Alexandra Loredana Suciu, ${ }^{1,2}$, Cătălin Perneș ${ }^{1}$, Camelia Giurgiu ${ }^{1}$, Ana-Maria Păcurar, ${ }^{1,}$, \\ Laura Șopterean², Mădălin Grigore ${ }^{1}$, Ioana Crișan ${ }^{1, "}$
}

\author{
${ }^{1}$ University of Agricultural Sciences and Veterinary Medicine from Cluj-Napoca, 400372 Cluj-Napoca, Romania \\ ${ }^{2}$ Agricultural Research and Development Station Turda, Agriculturii 27, 401100 Turda, Romania
}

\section{Current Trends in}

\section{Natural Sciences}

\begin{abstract}
Effectiveness of fungicide treatments during vegetation is recognized as important conditioning factor for the health of wheat crops. Furthermore, quantity and quality of the harvested grain are fundamentally affected by the health state of the crop during vegetation. Aim of this research was to identify the influence exercised by a gradient of fungicide treatments applied to wheat crop on seed mycosis susceptibility after harvest. Seeds belonging to three wheat cultivars ('Andrada', 'Codru', 'Exotic') that received a number of 0-3 fungicide treatments with some commonly used commercial products during vegetation (Credo, Evolus, Acanto Plus), were screened for germination rate, Alternaria sp. and Fusarium sp. incidence. Overall seed germination frequency was $96 \%$, Alternaria sp. frequency was $8.78 \%$ and Fusarium sp. frequency was $2.25 \%$. Seeds from the crop that received three fungicide treatments during vegetation displayed 5.38\% higher seed germination relative to control, decrease of Alternaria sp. frequency of $60.94 \%$ and decrease of Fusarium sp. frequency of $57.10 \%$ relative to control. Results suggest a decrease of seed mycotic load associated with increased number of fungicide treatments applied on the crop. Optimization of fungicide application might be possible by studying the influence of phenophase on the effectiveness of the treatments, and these aspects shall receive more attention in the future.
\end{abstract}

Keywords: fungi, grains, health, pathogen, quality.

\section{INTRODUCTION}

Wheat is one of the most important cereal crops worldwide as well as in Romania (Boiu-Sicuia et al., 2019). During last decade, the national wheat production showed an increasing trend. Statistical data shows that during the last decade the production almost doubled in Romania (MADR, 2021).

Wheat yield can vary from one year to another under the influence of a variety of factors such as climatic conditions, genotypes used, intensity of the attack by diseases and pests (Suciu et al., 2018). Several species of seed-borne fungi are known to cause damage to crop or stored wheat grains, such as fungi from genera: Fusarium, Microdochium, Bipolaris, Curvularia, Exserohilum, Alternaria, Aspergillus, Cladosporium, Penicillium, Stemphylium, Torula, Phoma, Septoria, Claviceps and Tilletia (Warham et al., 1996). Among the diseases caused by fungi, Fusarium head blight (FHB) is considered one of the most important for wheat because can cause up to $70 \%$ yield loss (Ye et al., 2017). In addition to seed-borne pathogenic fungi, wheat seeds can present other saprophytic fungi that are not causing pathogenesis to the crop but are secondary invaders, such as: Monilia, Myrothecium, Acremoniella, Arthrinium, Rhinotrichum, Stachybotrys, Ulocladium, 
Pestalotiopsis, Chaetomium, Melanospora, Sordaria and Rhizopus (Warham et al., 1996). Literature on mycoflora of wheat seeds gives particular attention to those microorganisms that present the potential to contaminate the grains with mycotoxins (Rozhkova et al., 2021). An important transmission way of fungal pathogens to the crop is through seeds (Perelló et al., 2016). Therefore, an important body of research is directed towards identification of appropriate seed treatments to reduce mycotic load of seeds sown and in order to limit the vertical transmission of the pathogens to the crop (Perelló et al.; Miclea et al., 2017; Sukut and Köycü, 2019; Boiu-Sicuia et al., 2019; Rozhkova et al., 2021). However, horizontal transmission is also an important cause of disease. This is mediated by insects, natural inoculum existing in the soil, and other ways that can cause pathogens to end up on the plant, infect plants during vegetation and cause specific pathologies, especially when weather conditions are favorable for pathogen establishment and growth. Strategies to mitigate mycotic disease in wheat crop range from cultural practices, biological control, fungicide application and sowing resistant genotypes (Perelló et al., 2016; Ye et al., 2017, Suciu et al., 2018). However, application of fungicide might range in effectiveness due to the development of resistance of the pathogen. In addition, fungicides are harmful to biota from agroecosystems and can pollute the environment. That is why rational application of fungicides is required (Perelló et al., 2016). This could be achieved by research directed towards optimization of their application.

Various industry sectors impose specific quality standards for wheat grains. In literature can be found more than 300 quality specifications for cereals and cereal products, out of which about 12 are applicable worldwide. Among these standards, specifications express requirements related to physical properties of wheat grains, damage level of grains as well as specifications and thresholds related to phytosanitary condition of grains (Proctor, 1994). Such specifications can be currently found in "wheat (Triticum aestivum L.) specification" ISO 7970:2021 (ISO, 2021). Such standards apply to wheat grains subject to trade or destined for consumption.

Because of the importance that phytosanitary condition of wheat grains has for starting new crops as well as for consumption of wheat products, control of mycotic load present on seed as well as screening of fungal contamination provides information with practical implications.

Aim of this research was to screen the influence of some commonly used fungicide products used on wheat crop, on germination and seed pathogens susceptibility after harvest. Three objectives were defined:

- determination of seed germination across treatments and cultivars

- determination of overall seed infection

- determination of seed infection with Alternaria sp. and Fusarium sp.

\section{MATERIALS AND METHODS}

Biologic material used in his study was represented by wheat seeds (Triticum aestivum) belonging to three cultivars ('Andrada', 'Codru' and 'Exotic') obtained from experimental field of the Agricultural Research and Development Station Turda, Romania, production of the year 2018.

Wheat was cultivated under conventional cultivation system, and during vegetation period were applied fungicide treatments (Table 1).

Thus, treatments were applied in the following phenophase: stem elongation (BBCH 31-32), booting-inflorescence emergence (BBCH 49-51), heading-flowering (BBCH 59-69), (Meier, 2018). Products applied were: Credo (chlorothalonil 500g/l + picoxystrobin 100g/l), Evolus (proquinazid $40 \mathrm{~g} / \mathrm{l}+$ tebuconazole 160g/l + prochloraz $320 \mathrm{~g} / \mathrm{l}$ ), Acanto Plus (cyproconazole 80g/l + 
picoxystrobin 200g/l) (https://www.glissando.ro). Application of the products followed the label instructions.

Table 1. Fungicide treatments applied to the wheat crop

\begin{tabular}{|l|c|c|c|c|}
\hline \multicolumn{2}{|c|}{ Treatments } & \multicolumn{3}{c|}{ Phenophase (Meier, 2018) } \\
\hline \multicolumn{1}{|c|}{ Abbreviation } & Number & BBCH 31-32 & BBCH 49-51 & BBCH 59-69 \\
\hline T0 (control) & - & - & - & - \\
\hline T1 & 1 & Credo & - & - \\
\hline T2 & 2 & Credo & Evolus & - \\
\hline T3 & 3 & Acanto Plus & Credo & Evolus \\
\hline
\end{tabular}

In 2019 was conducted the assessment of the mycotic load of the seeds. Unsterilized seeds (from the yield of 2018) were placed on moist blotter paper in Linhardt germination trays. Germination trays were sterilized before seeds were placed for germination. The blotter paper was soaked in distilled water. For each experimental variant were used 100 seeds in three replicates (Figure 1). After 4 days, were assessed the germination rate and infection occurrence. Based on observations was determined the germination, overall infection rate, Alternaria sp. and Fusarium sp. frequency for each cultivar. Fungi identification was conducted according to laboratory guide keys for fungi present on wheat seeds (Warham et al., 1996).
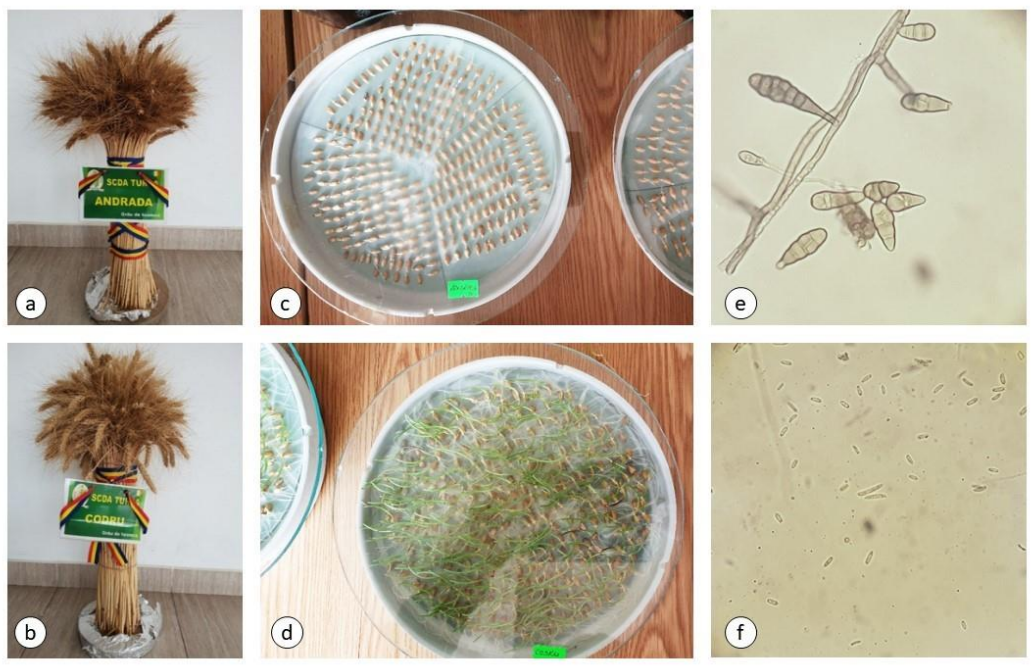

Figure 1. Wheat samples and microscopic examination: a-b) two Romanian wheat cultivars displayed at ARDS Turda, $c$ ) wheat seeds placed for germination, d) germinated seeds, e) Alternaria sp. under microscope, f) Fusarium sp. under microscope (Original)

\section{RESULTS AND DISCUSSIONS}

Analysis showed that average seed germination was $96 \%$ and with 5.38\% higher for seeds from the crop that benefited of three fungicide treatments during vegetation relative to the crop that did not receive any treatment. Regardless of treatments, overall germination rate was highest for cultivar 'Codru' (97.08\%), followed by 'Andrada' (95.68\%), and 'Exotic' (95.25\%). The average germination rate for seeds from the crop that received no fungicide treatments during vegetation 
was $93.00 \%$ (T0), for seeds from the crop that received one treatment at stem elongation phenophase the germination was $95.90 \%$ (T1), for seeds from crop that received two fungicide treatments during vegetation the germination was $97.10 \%$ (T2). Lastly, seeds from the crop that received three treatments during vegetation displayed highest germination: $98.00 \%$ (T3). This gradual pattern of increased seed germination following increased number of fungicide treatments during vegetation occurred in all the cultivars tested. Following application of three fungicide treatments, seed germination reached $98.00 \%$ in all three wheat cultivars studied. Following two treatments, the cultivar 'Andrada' displayed higher germination rate compared to the other two ('Codru', 'Exotic'), but following one fungicide treatment the cultivar 'Codru' had higher germination rate compared to the other two. When no fungicide treatments were applied to the crop, germination rate of the seeds harvested ranged between $91.00 \%$ ('Exotic') and $96.00 \%$ ('Codru') (Figure 2).

Observation of the seeds after incubation revealed that overall infection frequency of the seeds was $9.61 \%$ with a range between $3.00-15.70 \%$. For all three wheat cultivars the seed infection decreased with increased number of fungicide treatments applied to the crop. Following application of three treatments during vegetation (T3) caused an overall seed infection decrease of $55.78 \%$ relative to control (T0). Wheat cultivar 'Codru' showed a lower infection frequency at all treatment levels compared to the other two cultivars. Microscopic observation of main fungi that developed on the infected wheat seeds demonstrated these belonged to Alternaria sp. and Fusarium sp. These were found either solely or together on infected seed.
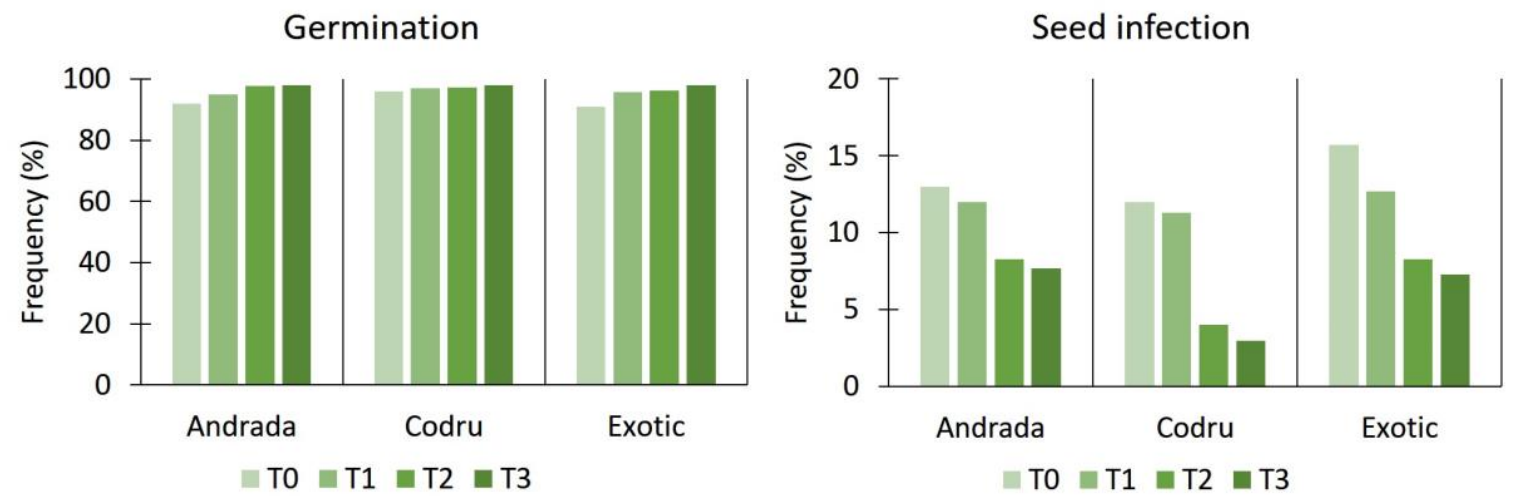

Figure 2. Wheat seeds germination and infection for three cultivars

Microscopic analysis confirmed an overall Alternaria sp. incidence in wheat seeds of $8.78 \%$, amounting to a decrease of incidence following three fungicide treatments of $60.94 \%$ relative to control. Regardless of treatments, overall Alternaria sp. frequency was lowest in cultivar 'Codru' (7.58\%) followed by 'Andrada' (7.78\%) and 'Exotic' (11.00\%). Seeds from the crop that received three fungicide treatments during vegetation presented an Alternaria sp. infection frequency of $5.00 \%$ (T3), seeds from the crop that received two treatments during vegetation presented an Alternaria sp. infection frequency of $6.00 \%$ (T2), seeds from the crop that received only one fungicide treatment presented an Alternaria sp. frequency of $11.33 \%$ (T1). When no fungicide treatments were applied the average Alternaria sp. frequency was $12.80 \%$ (T0). This pattern of decreased Alternaria sp. seed infection incidence with increased number of fungicide treatments, 
occurred for all three cultivars. Cultivar 'Exotic' maintained highest Alternaria sp. frequency at all treatment levels compared to the other two wheat cultivars followed by 'Codru' when one treatment or no treatment were applied. Cultivar 'Andrada' had lowest Alternaria sp. frequency compared to the other two cultivars when three, one or no treatment were applied (Figure 3).

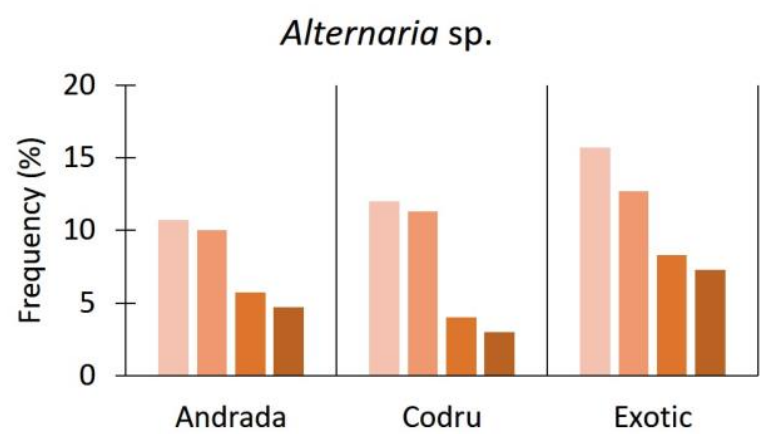

$=\mathrm{T} 0=\mathrm{T} 1=\mathrm{T} 2=\mathrm{T} 3$

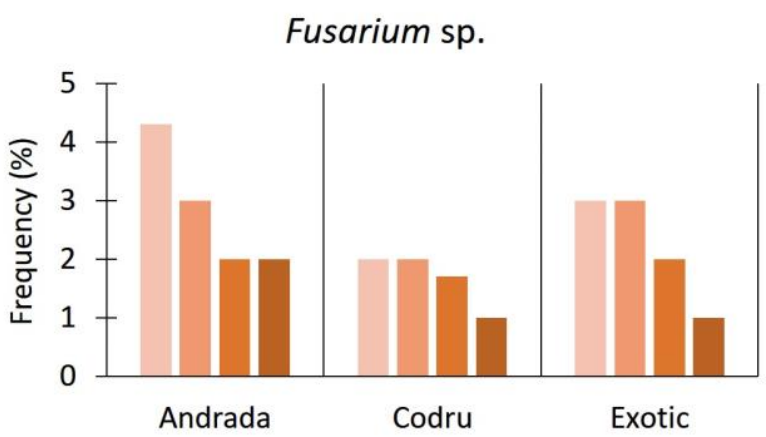

$\square \mathrm{T} 0 \mathrm{~T} 1 \mathrm{~T} 2 \mathrm{~T} 3$

Figure 3. Seed infection incidence with Alternaria sp. and Fusarium sp. in three wheat cultivars

Microscopic analysis confirmed an overall Fusarium sp. incidence in wheat seeds of $2.25 \%$, amounting to a decrease of incidence following three fungicide treatments of $57.10 \%$ relative to control. Regardless of treatments, overall Fusarium sp. frequency was lowest in cultivar 'Codru' (1.68\%) followed by 'Exotic' (2.25\%) and 'Andrada' (2.83\%). Seeds from the crop that received three fungicide treatments during vegetation presented a Fusarium sp. infection frequency of $1.33 \%$ (T3), seeds from the crop that received two treatments during vegetation presented a Fusarium sp. infection frequency of $1.90 \%$ (T2), seeds from the crop that received only one fungicide treatment presented a Fusarium sp. frequency of $2.67 \%$ (T1), and when no fungicide treatments were applied the average Fusarium sp. frequency was $3.10 \%$ (T0). This pattern of decreased Fusarium sp. seed infection incidence with increased number of fungicide treatments, occurred for all three cultivars, but the frequency did not change for all cultivars similarly. Thus, for cultivars 'Codru' and 'Exotic' the Fusarium sp. frequency remained the same for seeds from crops that received no treatment or one fungicide treatment. Similarly, cultivar 'Codru' showed no change in Fusarium sp. frequency for seeds from crop that received two or three treatments. When no treatment was applied, the Fusarium sp. frequency raged between $4.30 \%$ ('Andrada') and 2.00\% ('Codru'). When one or two fungicide treatment were applied, cultivars 'Andrada' and 'Exotic' both presented 3.00\% respectively $2.00 \%$ Fusarium sp. infection frequency. Following three fungicide treatments, seeds of the cultivars 'Codru' and 'Exotic' both displayed 1.00\% Fusarium sp. incidence. Lowest Fusarium sp. incidence occurred in seeds of 'Codru' compared to the other two cultivars at all treatment levels (Figure 3).

Results of this study have demonstrated that increased number of fungicide treatments applied on the crop decrease mycotic load of seeds at harvest. However, against Fusarium sp. frequency in the case of two cultivars ('Codru', 'Exotic'), one early treatment (applied at stem elongation phenophase) had same effectiveness against seed infection as no treatment, suggesting that application in later phenophase might have had more influence on seed mycotic load. Another interesting aspect was that for the cultivar 'Andrada' three treatments (including one at headingflowering stage) showed same effectiveness as two treatments (with latest applied at inflorescence emergence) against Fusarium sp. incidence in seeds. This indicated that further studies shall take 
into consideration the phenophase in order to find ways to optimize the application of fungicide treatments and achieve increased efficiency. Thus, phenophase might play an important role, since fungicide application at heading-flowering stage brought no additional improvement to the application from inflorescence emerging stage, as observed for 'Andrada' in this study. It is recommended that more cultivars should be tested in relation with these aspects in the future, because these can bring important insights with practical implications.

Seed-borne Fusarium sp. and Alternaria sp. fungi can cause diseases in wheat from seedling stage until maturity (Table 2).

Table 2. Pathogenicity of seed-borne Fusarium and Alternaria in wheat (Warham et al., 1996)

\begin{tabular}{|c|c|c|c|c|}
\hline Species & $\begin{array}{l}\text { Seedling } \\
\text { blight/rot }\end{array}$ & $\begin{array}{l}\text { Root, } \\
\text { foot, } \\
\text { crown rot }\end{array}$ & $\begin{array}{c}\text { Leaf } \\
\text { blight }\end{array}$ & $\begin{array}{c}\text { Head } \\
\text { blight/scab }\end{array}$ \\
\hline Fusarium avenaceum (Fr.) Sacc. & & $\mathrm{x}$ & & $\mathrm{x}$ \\
\hline Fusarium crookwellense Burgess, Nelson \& Toussoun & & & & $\mathrm{x}$ \\
\hline Fusarium culmorum (W.G. Sm.) Sacc. & $\mathrm{x}$ & $\mathrm{x}$ & & $\mathrm{x}$ \\
\hline Fusarium equiseti (Corda) Sacc. & $\mathrm{x}$ & $\mathrm{x}$ & & \\
\hline Fusarium graminearum Schwabe. & & $\mathrm{x}$ & & $\mathrm{x}$ \\
\hline Fusarium moniliforme J. Sheld & $\mathrm{x}$ & & & \\
\hline Fusarium poae (Peck) Wollenw. & & & & $\mathrm{x}$ \\
\hline Fusarium sambucinum Fuckel. & $\mathrm{x}$ & $\mathrm{x}$ & & \\
\hline Microdochium dimerum (Penz.) v. Arx & & $\mathrm{x}$ & & \\
\hline Microdochium nivale (Fr.) Samuels \& Hallett & $\mathrm{x}$ & $\mathrm{x}$ & & $\mathrm{x}$ \\
\hline Alternaria triticina Prasada \& Prabhu & & & $\mathrm{x}$ & \\
\hline
\end{tabular}

Similar with this study, another research conducted in same edapho-climatic conditions also demonstrated that 1-2 number of fungicide treatments on vegetation (tebuconazol + trifloxystrobin, tebuconazol + prothioconazole) in addition to seed treatment can significantly reduce the number of infected wheat seeds compared to the control, represented by seed treatment without foliar spraying treatment (Suciu et al., 2018). Research has shown that fungicide spraying with propiconazole during vegetation can significantly reduce the incidence of black point disease in wheat grains. Seed treatment with fungicides showed results that were not comparable in effectiveness with spraying treatments on vegetation (Malaker and Mian, 2009), highlighting the importance these have in mitigating consequences of horizontal transmittance of pathogens.

The application of the fungicide treatments on vegetation for wheat crop, contributes together with other agronomic management measures such as crop rotation and balanced fertilization to obtaining high yields (Suciu et al., 2018). Efficiency of fungicide applied to wheat crop against FHB - one of the most common and damaging wheat diseases, can present a variability due to timing of the application, method of application, virulence of the isolates or resistance of the wheat genotypes used. Using resistant wheat genotypes in conjunction with fungicide treatments appears to be most promising method of control (Ye et al., 2017). Time of application of fungicide is also important for the effective treatment (Suciu et al., 2018).

Although Alternaria sp. and Fusarium sp. are common mycotoxin-producing fungi that affect wheat, interactions between these fungi have been less studied in the past. Field experiment showed that fungicide (tebuconazole + prothioconazole) spraying on wheat during vegetation had a significant influence on Alternaria and Fusarium infected wheat seeds. Results of the same study also suggested the existence of stability of fungicide efficacy among experimental years in 
controlling $F$. graminearum but not Alternaria sp. Interestingly, there is evidence which indicates that increasing $F$. graminearum infection of wheat seeds over a threshold causes a decrease in Alternaria spp. incidence, hinting to a negative interaction (Jevtić et al., 2019).

Because mycotic load of the seeds is responsible for transmission of diseases to the wheat crop, various studies investigated the effectiveness of seed treatment, with different success rate. As seed treatment against $F$. culmorum, fungicide triticonazole + pyraclostrobin was shown to be effective (Sukut and Köycü, 2019). Another study demonstrated that fungicide treatments applied to wheat seeds can range in their effect on seedlings, from inhibition to stimulation of germination and seedling development (Rozhkova et al., 2021). Perelló et al. (2016) tested a range of biorational fungicides against Alternaria arborescens in a wheat seed treatment assay. Their results showed that some natural alternatives might present some good prospects such as: suspensions of Trichoderma harzianum and Epicoccum nigrum, diluted garlic juice and several salts (sodium bicarbonate, dibasic sodium phosphate, potassium chloride), while other formulations might be phytotoxic to plants at certain concentrations. Another study screened the inhibitory effect of over 10 hydroalcoholic plant extracts and some essential oils against Alternaria spp., Aspergillus spp., Penicillium spp., Fusarium spp. isolated from wheat seeds. Results attributed highest inhibitory effect to the tea tree essential oil against all the tested fungi, while the other treatments showed large range of variability for effectiveness (Miclea et al., 2017). Seed-treatments and naturally obtained products for the control of mycotic diseases in wheat crop represents an interesting area of research, but feasibility of these methods remains a challenge.

Integrated pest management (IPM) is considered the best approach in managing the agroecosystems in sustainable way and thus it is promoted by European Union through policies, regulations and guiding principles that constitute tools for achieving a cleaner environment and safer food products (IPM, https://ec.europa.eu). Such ambitious goals can be reached by using integrated approaches and optimizing the cultivation in such a way that high quantity and quality of production is still ensured. Because fungicide application remains the most effective way to prevent disease in crop and subsequently mycotoxin accumulation in grains, more research should be directed towards viable ways to reduce their use while also maintaining the standards for heathy crops and safe products. Such challenges can be tackled by sustained research efforts on this topic.

\section{CONCLUSIONS}

This study screened the influence of some commonly used fungicide products that are applied to wheat crop during vegetation, on seed mycosis susceptibility after harvest for three cultivars.

Results indicated a decrease of seed mycotic load associated with increased number of fungicide treatments applied to the crop. Following three fungicide treatments applied on the crop, seed infection frequency decreased with $60.94 \%$ for Alternaria sp. and $57.10 \%$ for Fusarium sp. relative to control (no treatment).

Germination rate ranged between $91.00 \%-98.00 \%$ and higher rate was associated with increased number of treatments for all three cultivars tested.

At all treatment levels lowest Fusarium sp. incidence occurred in 'Codru' seeds compared to the other two cultivars, while cultivar 'Exotic' maintained highest Alternaria sp. frequency at all treatment levels, compared to the other two cultivars studied.

Possibilities for the optimization of fungicide application shall receive more attention in the future, by studying the influence of phenophase on the effectiveness of the treatments. 


\section{Current Trends in Natural Sciences}

Vol. 10, Issue 19, pp. 58-65, 2021

https://doi.org/10.47068/ctns.2021.v10i19.007

Current Trends in Natural Sciences (on-line)

\section{REFERENCES}

Boiu-Sicuia, O.-A., Constantinescu, F., Ursan, M.-D., Cornea, C.P. (2019). Microbial inoculants applied as seed treatments and their effect on common wheat Triticum aestivum L. Annals of the University of Craiova Agriculture, Montanology, Cadastre Series 49, 2, 38-43

Jevtić, R., Župunski, V., Lalošević, M., Tančić Živanov, S. (2019). Colonization of winter wheat grain with Fusarium and Alternaria species and influence on pest control management. Journal of General Plant Pathology 85, 273 281.

Malaker, P.K., Mian, I.H. (2009). Effect of seed treatment and foliar spray with fungicides in controlling black point disease of wheat. Bangladesh Journal of Agricultural Research 34, 3, 425-434.

Meier, U. (2018) Growth stages of mono- and dicotyle-donous plants BBCH Monograph, Julius Kühn-Institut, Quedlinburg, DOI: 10.5073/20180906-074619.

Miclea, R., Suciu, L., Puia, C. (2017). Study regarding the efficacy of unconventional treatment products against the main wheat kernels pathogens. Bulletin USAMV series Agriculture 74, 2, 142-143.

Perelló, A., Lampugnani, G., Abramoff, C., Slusarenko, A., Bello, G.D. (2016). Suppression of seed-borne Alternaria arborescens and growth enhancement of wheat with biorational fungicides. International Journal of Pest Management 63, 2, 157-165.

Proctor, D.L. (1994). Grain storage techniques, Food and Agriculture Organization of the United Nations (FAO), Rome. ISBN 92-5-1 03456-7.

Rozhkova,T.O., Burdulanyuk, A.O., Bakumenko, O.M., Yemets, O.M., Vlasenko, V.A., Tatarynova, V.I., Demenko, V.M., Osmachko, O.M., Polozhenets, V.M., Nemerytska, L.V., Zhuravska, I.A., Matsyura, A.V., Stankevych, S.V. (2021). Influence of seed treatment on microbiota and development of winter wheat seedlings. Ukrainian Journal of Ecology 11, 1, 55-61.

Suciu, L., Șopterean L., Kadar, R., Mureșanu, F., Miclea, R., Florian, V., Puia, C. (2018). The influence of the number of fungicide treatments upon the quality and quantity of winter wheat yield in climatic conditions of Turda, Romania. Romanian Agricultural Research 35, 1-8.

Sukut F., Köycü, N.D. (2019). Effects of triazole and strobilurin-based fungicides on Fusarium culmorum on wheat, Journal of Agricultural Science 11(5), 16-22.

Warham, E.J., Butler, L.D., Sutton, B.C. (1996). Seed testing of maize and wheat - a laboratory guide, International Maize and Wheat Improvement Center (CIMMYT), Mexico.

Ye, Z., Brûlé-Babel, A.L., Graf, R.J., Mohr, R., Beres, B.L. (2017). The role of genetics, growth habit, and cultural practices in the mitigation of Fusarium head blight. Canadian Journal of Plant Science 97, 316-328.

***, Ministry of Agriculture and Rural Development (MADR), Wheat, Retrieved April 23, 2021 from https://www.madr.ro/culturi-de-camp/cereale/grau.

***, Fungicide products for crops, Retrieved April 23, 2021 from https://www.glissando.ro

***, International Organization for Standardization (ISO), Wheat, Retrieved April 23, 2021 from https://www.iso.org

***, Integrated Pest Management (IMP), Retrieved April 23, 2021 from https://ec.europa.eu 